\title{
Effect of Electrical Stimulation of Genioglossus Muscle on Upper Airway Resistance in Anesthetized Dogs
}

\author{
Hiroshi Miki, Wataru Hida, Chiyohiko Shindoh, \\ Osamu Taguchi, Hiroshi Inoue and Tamotsu Takishima \\ The First Department of Internal Medicine, Tohoku \\ University School of Medicine, Sendai 980
}

\begin{abstract}
Miki, H., Hida, W., Shindoh, C., Taguchi, O., Inoue, H. and Takishima, T. Effect of Electrical Stimulation of Genioglossus Muscle on Upper Airway Resistance in Anesthetized Dogs. Tohoku J. exp. Med., 1987, 153 (4), 397-398— The isolated upper airway pressure and flow changes during electrical stimulation of the genioglossus muscle in spontaneously breathing anesthetized dogs were measured at given pressures in the inspiratory direction. Upper airway resistance was maximal during no stimulation and decreased rapidly with stimulation at frequencies up to about $40 \mathrm{~Hz}$ — upper airway patency; sleep apnea
\end{abstract}

A possible involvement of the upper airway in the pathophysiologic mechanism in obstructive sleep apnea syndrome (OSAS) has been recently investigated (Remmers et al. 1978; Brouillette and Thach 1979). It has been proposed that upper airway patency depends on the balance of forces between chest wall muscle contraction and upper airway muscle contraction (Block et al. 1984). Specifically the genioglossus (GG) muscle, an upper airway muscle responsible for pulling the tongue forward, is thought to play an important role in maintaining the upper airway patency. However, there have been no reports of how an increase in GG muscle activity affects the patency of the upper airway. Accordingly, in this study we examined upper airway resistance (Raw) caused by augmentation of GG muscle activity.

Six spontaneously breathing mongrel dogs $(12-15 \mathrm{~kg})$ were anesthetized with pentobarbital sodium $(25 \mathrm{mg} / \mathrm{kg}$, i.v.) and placed in the supine position. The upper airway was isolated from the lower airway and the chest wall by transecting the cervical trachea about $5 \mathrm{~cm}$ below the larynx. Two needle electrodes were perorally inserted in the GG muscle. Upper airway flow was measured at constant driving pressure $\left(5,10\right.$, and $\left.20 \mathrm{cmH}_{2} \mathrm{O}\right)$ toward inspiratory direction, while the $\mathrm{GG}$ muscle was stimulated with electric pulses of 10-20 V and 0.2 msec duration at different frequencies (from 5 to $100 \mathrm{~Hz}$ ) during 5 consecutive breaths.

Upper airway flow showed phasic changes corresponding to the respiratory cycle. The point of maximal flow was defined as "opened" and that of minimal flow as "narrowed". Fig. 1 shows the relationship between stimulation frequency and opened Raw of the three given driving pressures in a typical experiment. Opened and narrowed Raw were progres-

Received September 28, 1987 ; accepted for publication October 23, 1987.

Send correspondence to : Tamotsu Takishima, M.D., Professor and Chairman, the First Department of Internal Medicine, Tohoku University School of Medicine, 1-1 Seiryo-machi, Sendai 980, Japan. 


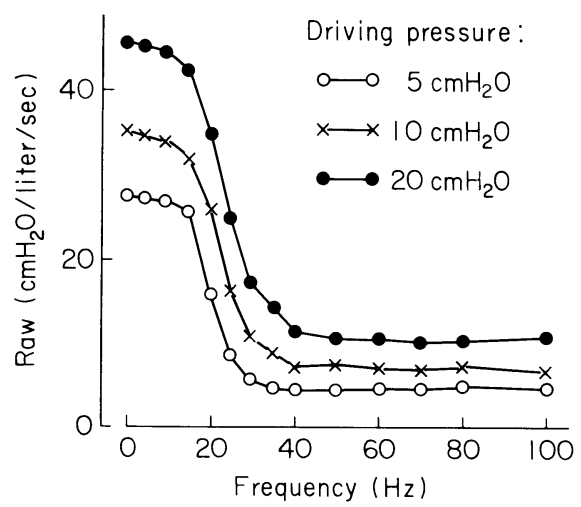

Fig. 1. Relationship between genioglossus muscle stimulation frequency and opened upper airway resistance (Raw) of a dog.

sively dilated with increasing stimulation frequency of the GG muscle up to $40 \mathrm{~Hz}$, and above $50 \mathrm{~Hz}$ the upper airway was maximally dilated. Raw increased as suction force (driving pressure) in the upper airway become larger at each stimulation frequency. Similar results were obtained from 5 other dogs.

The present results suggest that GG muscle activity is important in maintaining the patency of upper airway, and may shed some light on developing treatment for patients with OSAS.

\section{References}

1) Block, A.J., Faulkner, J.A., Hughes, R.L., Remmers, J.E. \& Thach, B.T. (1984) Factors influencing upper airway closure. Chest, 86, 114-122.

2) Brouillette, R.T. \& Thach, B.T. (1979) A neuromuscular mechanism maintaining extrathoracic airway patency. J. appl. Physiol., 46, 772-779.

3) Remmers, J.E., deGroot, W.J., Sauerland, E.K. \& Anch, A.M. (1978) Pathogensis of upper airway occlusion during sleep. J. appl. Physiol., 44, 931-938. 